\title{
Transcriptional Onset of Lysozyme Genes during Early Development in Olive Flounder (Paralichthys olivaceus)
}

\author{
Jang-Wook Lee, ${ }^{\dagger}$ Jeong-Ho Lee, Jae Koo Noh, Hyun Chul Kim, Choul-Ji Park, \\ Jong-Won Park and Kyung-Kil Kim \\ Genetics and Breeding Research Center, NFRDI, Geoje 656-842, Korea
}

\begin{abstract}
The immune system in teleost fish is not completely developed during embryonic and larval stages, therefore effective innate mechanisms is very important for survival in such an environment. However, the knowledge of the development of immune system assumed to be restricted. In many species, lysozymes have been considered as important genes of the first line immune defense. The early detection of lysozyme mRNA in previous reports, led to the investigation of its presence in oocytes. As a result, c-type lysozyme mRNA transcripts were detected in unfertilized oocytes indicating maternal transfer. Therefore, we investigated the expression patterns of lysozymes in flounder, including the matured oocyte. In our results, c-type lysozyme mRNA was first detected in unfertilized oocyte stage, observed the significantly decreased until hatching stage, and was significantly increased after hatching stage. On the other hand, g-type lysozyme mRNA transcripts were first detected at late neurula stage, and the mRNA level was significantly increased after 20 dph. It may be suggest that maternally supplied mRNAs are selectively degraded prior to the activation of embryonic transcription. This study will be help in understanding the maturation and onset of humoral immunity during development of olive flounder immune system.
\end{abstract}

Key words : Olive flounder (Paralichthys olivaceus), Lysozyme, Development, Expression, Maternal transfer

\section{INTRODUCTION}

Lysozyme is one of the several antimicrobial enzymes, associated the first line immune defense parameter and is widely distributed in invertebrates and vertebrates. It is bactericidal in nature that catalyzes the hydrolysis of the $\beta$ 1,4-glycosidic linkage between N-acetylmuramic acid (NAM) and $\mathrm{N}$-acetylglucosamine (NAG) alternating sugar residues in the bacterial peptidoglycan, and causes bacterial cell lysis (Bachali et al., 2002). The main sources of fish lysozymes are generally believed to be of leukocyte origin (monocytes, macrophages and neutrophils) (Lie et al., 1989; Cecchini et al., 2000).

In vertebrates, there are two types of lysozyme, chickentype (c-type) and goose-type (g-type) (Jollès \& Jollès, 1984). In fish, c-type and g-type lysozymes have been identified from various species during last decades and lysozyme activity has been reported in different lymphoid tissues, kidney, gills and intestine (Saurabh \& Sahoo, 2008). Ctype lysozymes have been isolated from many vertebrates and insects (Prager \& Jollès, 1996, Qasba \& Kumar, 1997). In teleost fish, lysozymes have been characterized in olive

\footnotetext{
Manuscript received 24 November 2014, Received in revised form 1 December 2014, Accepted 2 December 2014

${ }^{\dagger}$ Corresponding Author : Jeong-Ho Lee, Genetics and Breeding Research Center, NFRDI, Geoje 656-842, Korea. Tel : +82-55-639-5811, Fax : +82-55639-5809, E-mail : jhlee7124@korea.kr

This is an Open Access article distributed under the terms of the Creative Commons Attribution Non-Commercial License (http:// creativecommons.org/licenses/by-nc/3.0) which permits unrestricted non-commercial use, distribution, and reproduction in any medium, provided the original work is properly cited.
} 
flounder (Hikima et al., 1997), brill (Jiménez-Cantizano et al., 2008), grass carp (Ye et al., 2010), orange-spotted grouper (Wei et al., 2012), and kelp grouper (Harikrishnan et al., 2011).

G-type lysozymes have also been characterized in four avian species, goose, chickens, black swans and ostriches (Simpson \& Morgan, 1983; Nakano \& Graf, 1991; Simpson et al. 1980; Schoentgen et al., 1982). The first report of a g-type lysozyme in fish was in olive flounder (Hikima et al., 2001), followed by other fish such as orange-spotted grouper (Yin et al., 2003), large yellow croaker (Zheng et al., 2007), Atlantic cod (Larsen et al., 2009), grass carp (Ye et al., 2010) and catfish (Wang et al., 2013). In a recent study, several studies was observed that up-regulation of g-type lysozyme was much stronger than ctype lysozyme after in vitro and in vivo stimulation with lipopolysaccharide (LPS) or challenge with bacterial pathogens, whereas c-type might be main molecule for housekeeping defense under normal conditions (Jimenez-Cantizano et al., 2008; Larsenet al., 2009; Ye et al., 2010).

Olive flounder (Paralichthys olivaceus) is recognized as economically important marine fish and successfully cultured in Japan, China and Korea. Recently, this species faces significant high mortality especially in early developmental stage, which attracted our interest to characterize how their immune system works during the development stages. In fishes, larvae are immediately exposed to various pathogens after hatching (Zapata et al., 1997). However, the immune system is still developing and not all of the structures and functions present in the adults are in the larvae (Ellis, 1988; Tatner, 1996). Therefore, knowledge of the immune system in ontogeny can offer new protective strategies and indicate optimal vaccination point (Vadstein, 1997).

Previous studies show that lysozyme has been detected in oocytes, fertilized eggs and larval stages of several fish species including tilapia (Brown et al., 1997), salmonids
(Medzhitov et al., 2000), sea bass (Cecchini et al., 2000), Atlantic cod (Seppola et al., 2009) and rohu (Nayak et al., 2011). Although the lysozyme genes has been reported in several fish, considerably less is known about the expression of different types of lysozymes during early developmental stages in olive flounder. The expression study of lysozyme genes during ontogenesis will help in understanding the maturation and onset of humoral immunity during development of olive flounder immune system. Therefore, we investigate the expression pattern analysis of c-type and g-type lysozyme in early developmental stages, and tissue-specific expression study in immune organ.

\section{MATERIALS AND METHODS}

\section{Sample preparation}

Larvae and adult flounder was collected from Genetics and Breeding Research Center, National Fisheries Research and Development Institute (NFRDI; Geoje, Republic of Korea), and maintained in 10 tons flow through tank at $20 \pm 1{ }^{\circ} \mathrm{C}$ under a natural photoperiod. The tissue samples was prepared from various tissues including brain, muscle, fin, eye, liver, gill, kidney, and spleen obtained from healthy olive flounder $(n=3)$. Eggs were collected from different developmental stages of embryo $(\sim 0.92 \mathrm{~mm})$ including unfertilized oocyte (UFO), fertilized egg (F), 116 cells (E1), molura (E2), blastula (E3), gastrula (E4), early neurula (E5), late neurula (E6), and lavae were collected from eight laval stages $(\sim 2.49 \mathrm{~mm})$ including 0,5 , $10,15,20,30,40$ and 50 days post hatching (dph) fish kept at $18.0^{\circ} \mathrm{C}$ in the sea-water tank. All the samples were collected in Trizol Reagent (Invitrogen) aseptically and preserved at $-80^{\circ} \mathrm{C}$ until RNA extraction.

\section{Isolation of RNA and cDNA synthesis}

Total RNA was extracted from 50 to $100 \mathrm{mg}$ using Trizol Reagent (Invitrogen), as per manufacturer's instructions, 
and suspended in DEPC-treated water for RT-PCR. Total RNA concentration was quantified by spectrophotometer and 1-2 $\mu \mathrm{g}$ of total RNA was used for reverse transcribed into cDNA using First Strand cDNA synthesis kit (Roche). The amplification was performed with AmpliTag Gold DNA Polymerase (Applied Biosystems) in thermal Cycler (Applied Biosystems) using the following parameters: denaturation at $95^{\circ} \mathrm{C}$ for $10 \mathrm{~min}$ and 35 cycles of reactions of denaturation at $98^{\circ} \mathrm{C}$ for $10 \mathrm{sec}$, annealing at $58^{\circ} \mathrm{C}$ for $30 \mathrm{sec}$, and elongation at $72^{\circ} \mathrm{C}$ for $30 \mathrm{sec}$. An aliquot of each PCR product was subjected to $1.2 \%$ agarose gel electrophoresis and visualized by staining with ethidium bromide.

All the primers were designed using bundle software, Primer express (version 3.0). The gene specific primers are listed in Table 1.

\section{Expression studies}

To evaluate mRNA levels of c-type and g-type lysozyme, primers were specifically designed to detect and quantify cDNA sequences without detecting genomic DNA. The real-time PCR reactions were monitored with melting curve analysis using 7500 software (version 2.0.5). Amplification efficiency was determined by serial dilutions. All experiments were repeated in tri-replicate. Each reactions displayed an efficiency $92.9 \%\left(\mathrm{R}^{2}=0.982\right), 90.7 \%\left(\mathrm{R}^{2}=0.964\right)$ and $98.0 \%\left(\mathrm{R}^{2}=0.999\right)$, c-type, g-type and $\beta$-actin, respectively.

Real-time PCR reaction mixture contained $2 \mu \mathrm{L}$ of diluted cDNA sample, specific primer and the FAST SYBR Green
PCR Master Mix (Applied Biosystems). The reactions for the amplification of each genes was subjected to an initial denaturation at $95^{\circ} \mathrm{C}$ for $20 \mathrm{sec}$, annealing at $58^{\circ} \mathrm{C}$ for 30 sec, and elongation at $60^{\circ} \mathrm{C}$ for $30 \mathrm{sec}$. Thermal cycling and fluorescence detection were conducted using the 7500 Fast Real-Time PCR system (Applied Biosystems).

Expression of lysozyme genes was normalized to an endogenous reference $\beta$-actin and presented as subtraction of target $\mathrm{CT}$ values from $\beta$-actin $\mathrm{CT}$ values ( $\Delta \mathrm{CT}$ value). Comparison of gene expression between tissues and calibrator was derived from subtraction of the calibrator $\Delta \mathrm{CT}$ values from the target $\Delta \mathrm{CT}$ values to give a $\Delta \Delta \mathrm{CT}$ value, and relative gene expression was calculated to determine fold difference $\left(2^{-\Delta \Delta \mathrm{CT}}\right)$.

\section{Statistical analysis}

The data are presented as the mean \pm standard deviation. The mRNA levels of lysozyme genes were expressed as a ratio to those $\beta$-actin, which was simultaneously amplified as an internal control for each cDNA. The data was statistically analyzed by one-way ANOVA after arcsine transformation when needed, and followed by a Tukey's test for identification of the statistically distinct groups. Significant differences were accepted for $P<0.05$.

\section{RESULTS}

1. Expression of lysozymes from various tissues

Table 1. Sequences of primers used for the RT-PCR

\begin{tabular}{cccc}
\hline \hline Gene & Primer & Sequence (5'- 3') & GenBank accession no. \\
\hline \multirow{2}{*}{$\beta$-actin } & Forward & GAGCGTGGCTACTCCTTCAC & CX725848 \\
& Reverse & AGGAAGGAAGGCTGGAAGAG & AB050469 \\
\hline \multirow{2}{*}{ C-type lysozyme } & Forward & ACTGAGTGGGAGTCACACTACAAC & AB050591 \\
& Reverse & ACCACTCTTTTGGCACATTTG & \\
\hline \multirow{2}{*}{ G-type lysozyme } & Forward & CCAGGGCTGGAAATCAACT & ACTTGGTTCTGATTCGCTCAA \\
\hline
\end{tabular}


In previous study, c-type lysozyme gene was expressed mainly in kidney, spleen, brain and ovary (Hikima et al., 1997), whereas the g-type was detected in kidney, spleen, skin, muscle, heart and brain (Hikima et al., 2001) using northern blot analysis. Such results are now confirmed by the detection of lysozyme in various tissues by real-time PCR analysis of olive flounder.

In order to investigate of c-type and g-type lysozyme mRNA expression in various tissues from healthy flounder, oligonucleotide specific primers were designed according to previously reported both genes in olive flounder (GenBank accession no. AB050469 and AB050591, respectively) (Table 1). Gene expression levels were normalized with respect to $\beta$-actin and brain mRNA was employed as calibrator. C-type lysozyme was highly expressed in spleen, kidney, gill and brain (7.6-, 5.5- and 1.5-fold higher than in the brain, respectively). In contrast, g-type lysozyme was expressd ubiquitously in transcript level in all tissues. The highest level was expressed in spleen and kidney (6.2- and 5.3-fold higher than in the brain, respectively). These

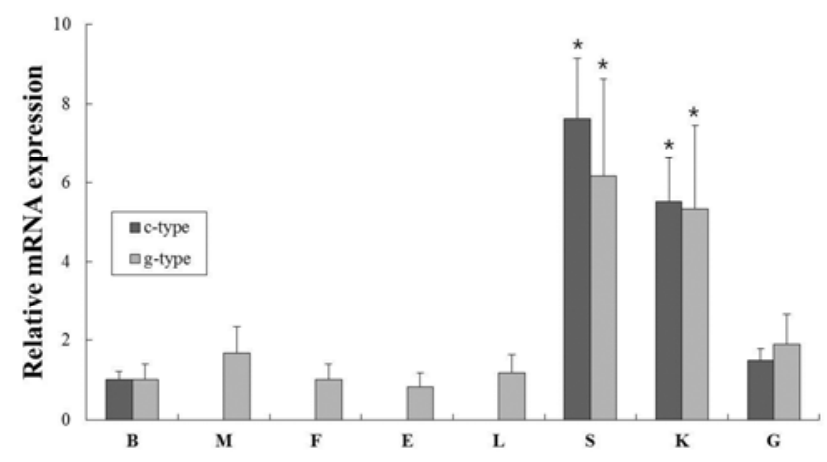

Fig. 1. Normal tissue distribution of lysozymes mRNA in various tissues. A quantitative real-time PCR analysis was performed with equal amounts of total RNA from the tissues of healthy olive flounders. $\beta$ actin was used as an internal control. Different letters over each bar with the standard deviation represent significant differences one group according to unpaired matched comparisons $(* P<0.05)$. B, brain; M, muscle; F, fin; E, eye; L, liver; Sp, spleen; $\mathrm{K}$, kidney; G, gill. overall patterns of lysozyme genes were highly expressed in spleen and kidney, similar to previous studies (Fig. 1). The spleen and kidney (anterior and middle) are one of largest lymphoid organs and phagocytic organ in teleost fish (Zapata et al., 2006).

\section{Expression of lysozymes during early development}

All samples were technically triplicated samples, and target genes were standardized using reference gene $\beta$ actin for mRNA expression study. The expression pattern of the c-type and g-type lysozyme genes were investigated over time course UFO, F, E1 to E6 (egg stages) and 0 to 50 days post hatching (larval stages) of olive flounder using real-time PCR.

In our study, the c-type lysozyme mRNA transcripts were detected in unfertilized oocytes (UFO), but not detected in g-type lysozyme (Fig. 2). Studies on several fish species have shown that lysozyme genes are transferred from the mother to the offspring (Yousif et al., 1994, 1994; Wang \& Zhang, 2010), and it may be involved in the early defense against pathogen in eggs containing developing embryo and larvae.

C-type lysozyme expression was highly detected at unfertilized oocyte (UFO), and significantly decrease until around hatching stage $(0 \mathrm{dph})$. After hatching, transcrip-

\section{C-type lysozyme}

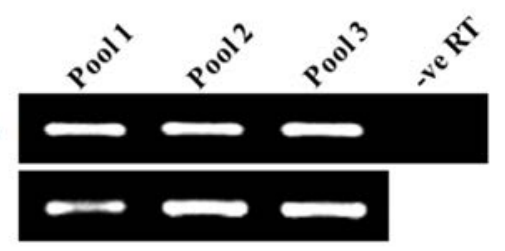

Fig. 2. Expression of c-type lysozyme mRNA in unfertilized oocytes. Represents the expression of c-type lysozyme and $\beta$-actin in unfertilized oocytes measured in three separate pools. The negative (-ve) RT controls contain RNA from each time point that was not reverse transcribed and therefore acts as evidence that the samples were free of contaminating genomic DNA. 


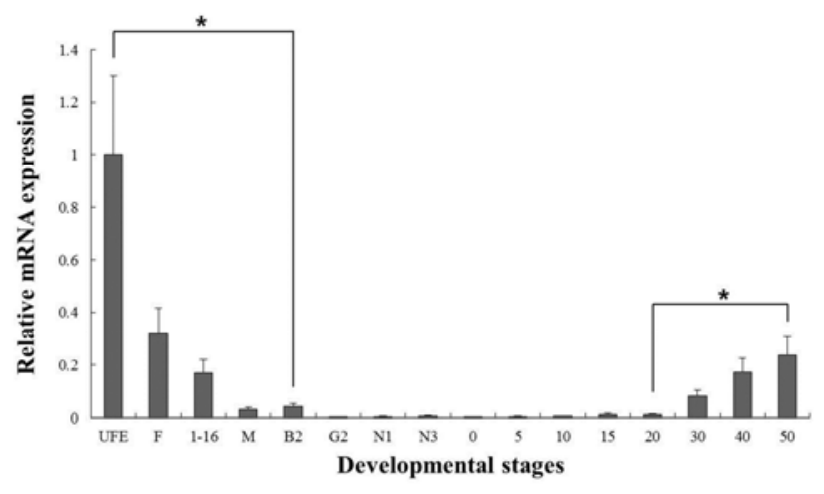

Fig. 3. Expression of c-type lysozyme mRNA at differrent developmental stages. The mRNA expression of c-type lysozyme was analyzed by real-time PCR during the embryonic and larval stages including unfertilized oocyte (UFO) to 50 days post hatching (dph). Different letters over each bar with the standard deviation represent significant differences one group according to unpaired matched comparesons $\left({ }^{*} P<0.05\right)$. UFO, unfertilized oocyte; $\mathrm{F}$, fertilized egg; E1, 1-16 cells; E2, molura; E3, blastula; E4, gastrula; E5, early neurula; E6, late neurula; and 0 to 50 days post hatching (dph).

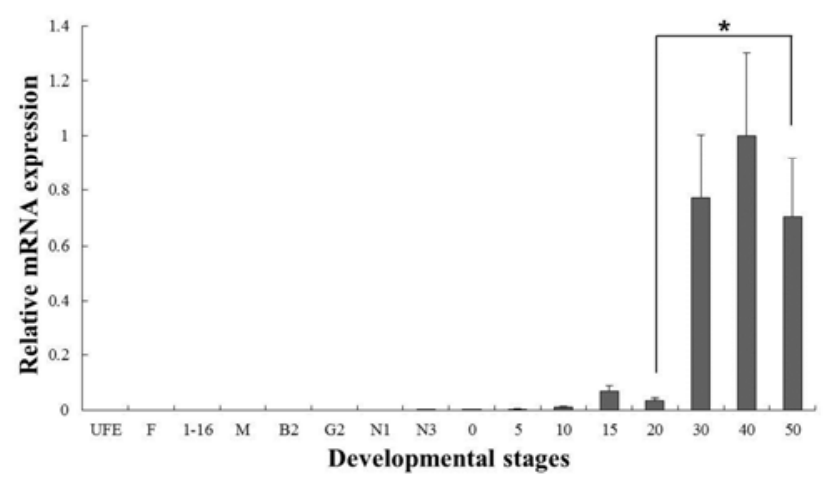

Fig. 4. Expression of g-type lysozyme mRNA at differrent developmental stages. Relative mRNA levels of g-type lysozyme at different developmental stages of $P$. olivaceus by using real-time PCR analysis. Different letters over each bar with the standard deviation represent significant differences one group according to unpaired matched comparisons $(* P<0.05)$. UFO, unfertilized oocyte; $\mathrm{F}$, fertilized egg; E1, 1-16 cells; E2, molura; E3, blastula; E4, gastrula; E5, early neurula; E6, late neurula; and 0 to 50 days post hatching (dph). tion level was significantly increased in 30 to $50 \mathrm{dph}$ (Fig. 3). G-type lysozyme mRNA transcripts were first detected at late neurula (E6), and the transcription level was drastically increased after the $20 \mathrm{dph}$. The intensity of g-type lysozyme transcript was measured on the basis of E6 (1.0fold), each value has the $30 \mathrm{dph}$ (1583-fold), $40 \mathrm{dph}$ (2051-fold) and 50 dph (1445-fold), respectively (Fig. 4).

\section{DISCUSSIONS}

The fish immune system is not fully developed during early embryonic stages and the immunological capacity is thus assumed to be limited. C-type and g-type lysozyme genes have revealed as useful markers to study the effect of environment contaminants (Mondon et al., 2000; Skouras et al., 2003; Nakayama et al., 2007), immunostimulants (Ashihida \& Okimasu, 2005; Alvarez-Pellitero et al., 2006) as well as bacterial pathogens (Hikima et al., 2001; Minagawa et al., 2001) on the immune response in teleost fish. Therefore their levels of expression can help from the problem of high mortality in olive flounder larvae.

In our study, c-type and g-type lysozyme was investigated in various tissues including brain, muscle, fin, eye, liver, gill, kidney, and spleen (Fig. 1). The results are expressed predominantly in hematopoietic tissues (spleen and kidney). In previous study, fish lysozyme is generally believed to be of leucocyte origin (Lie et al., 1989; Cecchini et al., 2000), and localization of lysozyme in prelarvae, before the onset of feeding, has been studies in tilapia using immunohistochemistry (Takemura, 1996). In many species, lysozymes seem to be ubiquitously expressed in most tissues. However, few studies of lysozymes are reported that is specifically expressed. In cows, c-type lysozymes are differentiated by their function and tissue expression patterns as stomach and non-stomach lysozymes (Irwin 1996, 2004). Moreover, in zebrafish (Liu \& Wen, 2002) and in rohu (Nayak et al., 2011), those are specifically expressed in the myeloid lineage and hematopoietic 
tissues, respectively. The g-type lysozyme is also reported with tissue-specific expression in chicken, whose g-type lysozyme gene is expressed in bone marrow and lung (Nakano et al., 1991).

In several studies, the patterns of lysozymes expression level, they did not follow the trend of an initial increase in larval stage. Therefore, we have included the investigations of maternal mRNA transfer into oocytes in unfertilized eggs. As a result, we found that expressing of c-type lysozyme mRNA transcripts in unfertilized oocytes, but not expressed in g-type lysozyme (Fig. 2). Also, c-type lysozyme mRNA was first detected in unfertilized oocyte (UFO) stage, observed the significantly decreased mostly until hatching stage $(\mathrm{H})$, and was significantly increased in 30 to $50 \mathrm{dph}$ after hatching stage (Fig. 3). On the other hand, gtype lysozyme mRNA transcripts were first detected at late neurula (E6) stage, and the mRNA level was significantly increased after $20 \mathrm{dph}$ (Fig. 4). In zebrafish, maternally supplied mRNAs are selectively degraded prior to the activation of embryonic transcription. This occurs in order to transfer developmental control to the zygote genome and a correctly timed clearance of maternal transcripts is critical for embryogenesis (Giraldez et al., 2006). After hatching stages, the mRNA level of c-type lysozyme was increased significantly indicating that from this period the embryo independently produces its own transcripts and the use of maternally derived lysozyme may be of less importance.

In summary, this study provides new information of lysozymes mRNA expression during the early developmental stage in olive flounder. Although it is still not clear whether presence of components of the immune system confer any protection against pathogens, maternal supply and early expression may indicate an important function during the early stages of development in olive flounder.

\section{ACKNOWLEDGEMENT}

This work was supported by a grant from the National Fisheries Research and Development Institute (NFRDI), contribution number RP-2014-BT-053.

\section{REFERENCES}

Alvarez-Pellitero P, Sitja-Bobadilla A, Bermudez R, Quiroga MI (2006) Levamisole activates several innate immune factors in Scophthalmus maximus (L.) Teleostei. Int J Immunopathol Pharmacol 19:727-738.

Ashida T, Okimasu E (2005) Immunostimulatory effects of fermented vegetable product on the non-specific immunity of Japanese flounder Paralichthys olivaceus. Fish Sci 71:257-262.

Bachali S, Jager M, Hassanin A, Schoentgen F, Jolles P, Fiala-Medioni A, Deutsch JS (2002) Phylogenetic analysis of invertebrate lysozymes and the evolution of lysozyme function. J Mol Evol 54:652-664.

Brown LL, Cox WT, Levine RP (1997) Evidence that the causal agent of bacterial coldwater disease Flavobacterium psychrophilum is transmitted within salmonid eggs. Dis Aquat Organ 29:213-218.

Cecchini S, Terova G, Caricato G, Saroglia M (2000) Lysosome activity in embryos and larvae of sea bass (Dicentrarchus labrax L.), spawned by broodstocks fed with vitamin $\mathrm{C}$ enriched diets. Bull Eur Assoc Fish Pathol 20:120-124.

Ellis AE (1988) Ontogeny of the immune system in teleost fish. In: Ellis AE (ed) Fish Vaccination Academic Press London pp20-31.

Giraldez AJ, Mishima Y, Rihel J, Grocock RJ, Van Dongen S, Inoue K, Enright AJ, Schier AF (2006) Zebrafish MiR-430 promotes deadenylation and clearance of maternal mRNAs. Science 312:75-79.

Harikrishnan R, Kim JS, Kim MC, Balasundaram C, Heo MS (2011) Molecular characterization, phylogeny, and expression pattern of c-type lysozyme in kelp grouper 
Transcriptional Onset of Lysozyme Genes during Early Development in Olive Flounder (Paralichthys olivaceus)

(Epinephelus bruneus). Fish Shellfish Immunol 31: 588-594.

Hikima J, Hirono I, Aoki T (1997) Characterization and expression of c-type lysozyme cDNA from Japanese flounder (Paralichthys olivaceus). Mol Mar Biol Biotechnol 6:339-344.

Hikima J, Minagawa S, Hirono I, Aoki T (2001) Molecular cloning, expression and evolution of the Japanese flounder goose-type lysozyme gene, and the lytic activity of its recombinant protein. Biochim Biophys Acta 1520:3544.

Irwin DM (1996) Molecular evolution of ruminant lysozymes. EXS 75:347-361

Irwin DM (2004) Evolution of cow nonstomach lysozyme genes. Genome 47:1082-1090.

Jimenez-Cantizano RM, Infante C, Martin-Antonio B, Ponce M, Hachero I, Navas JI, Manchado M (2008) Molecular characterization, phylogeny, andexpression of c-type and g-type lysozymes in brill (Scophthalmus rhombus). FishShellfish Immunol 25:57-65.

Jollés P, Jollés J (1984) What's new in lysozyme research? Always a model system, today as yesterday. Mol Cell Biochem 63:165-189.

Larsen AN, Solstad T, Svineng G, Seppola M, Jorgensen TO (2009) Molecular characterization of a goose-type lysozyme gene in Atlantic cod (Gadus morhua L.). Fish Shellfish Immunol 26:122-132.

Lie Ø, Evensen Ø, Sørensen A, Frøysadal E (1989) Study on lysozyme activity in some fish species. Dis Aquat Org 6:1-5.

Liu F, Wen Z (2002) Cloning and expression pattern of the lysozyme C gene in zebrafish. Mech Dev 113:69-72.

Medzhitov R, Janeway CA (2000) Innate immune recognition: mechanisms and pathways. Immunol Rev 173:8997.

Minagawa S, Hikima J, Hirono I, Aoki T, Mori H (2001) Expression of Japanese flounder c-type lysozyme cDNA in insect cells. Dev Comp Immunol 25:439-445.

Mondon JA, Duda S, Nowak BF (2000) Immune response of greenback flounder Rhombosolea tapirina after exposure to contaminated marine sediment and diet. Mar Environ Res 50:443-450.

Nakano T, Graf T (1991) Goose-type lysozyme gene of the chicken: sequence, genomic organization and expression reveals major differences to chicken-type lysozyme gene. Biochim Biophys Acta 1090:273-276

Nakayama A, Kurokawa Y, Harino H, Kawahara E, Miyadai T, Seikai T, Kawai S (2007) Effects of tributyltin on the immune system of Japanese flounder (Paralichthys olivaceus). Aquat Toxicol 83:126-133.

Nayak SP, Mohanty BR, Mishra J, Rauta PR, Das A, Eknath AE, Sahoo PK (2011) Ontogeny and tissuespecific expression of innate immune related genes in rohu, Labeo rohita (Hamilton). Fish Shellfish Immunol 30:1197-1201.

Prager EM, Jollés P (1996) in: Jollés P (Ed) Lysozymes; Model Enzymes in Biochemistry and Biology. Birkhäuser Verlag Basel pp9-31.

Qasba PK, Kumar S, Brew K (1997) Molecular divergence of lysozymes and $\alpha$-Lactalbumin. Crit Rev Biochem Mol Biol 32:255-306.

Saurabh S, Sahoo PK (2008) Lysozyme: an important defence molecule of fish innate immune system. Aquac Res 39:223-239.

Schoentgen F, Jollés J, Jollés P (1982) Complete amino acid sequence of ostrich (Struthio camelus) egg-white lysozyme, a goose-type lysozyme. Eur J Biochem 123: 489-497.

Seppola M, Johnsen H, Mennen S, Myrnes B, Tveiten H (2009) Maternal transfer and transcriptional onset of immune genes during ontogenesis in Atlantic cod. Dev Comp Immunol 33:1205-1211.

Simpson RJ, Begg GS, Dorow DS, Morgan FJ (1980) Complete amino acid sequence of the goose-type ly- 
sozyme from the egg white of the black swan. Biochemistry 19:1814-1819.

Simpson RJ, Morgan FJ (1983) Complete amino acid sequence of embden goose (Anwer anwer) egg-white lysozyme. Biochim Biophys Acta 744:349-351.

Skouras A, Lang T, Vobach M, Danischewski D, Wosniok W, Scharsack JP, Steinhagen D (2003) Assessment of some innate immune responses in dab (Limanda limanda L.) from the North Sea as part of an integrated biological effects monitoring. Helgoland Mar Res 57:181189.

Takemura A (1996) Immunohistochemical localization of lysozyme in the prelarvae of tilapia (Oreochromis mossambicus). Fish Shellfish Immunol 6:75-77.

Tatner MF (1996) Natural changes in the immune system of fish. In: Iwama, G, Nakanishi T (Eds) The Fish Immune System Organism, Pathogen and Environment. Academic Press San Diego CA pp255-287.

Vadstein O (1997) The use of immunostimulation in marine larviculture: possibilities and challenges. Aquaculture 155:401-417.

Wang R, Feng J, Li C, Liu S, Zhang Y, Liu Z (2013) Four lysozymes (one c-type and three g-type) in catfish are drastically but differentially induced after bacterial infection. Fish Shellfish Immunol 35:136-145.

Wei S, Huang Y, Cai J, Huang X, Fu J, Qin Q (2012) Molecular cloning and characterization of c-type lysozyme gene in orange-spotted grouper (Epinephelus coioides). Fish Shellfish Immunol 33:186-196.

Ye X, Zhang L, Tian Y, Tan A, Bai J, Li S (2010) Identification and expressionanalysis of the g-type and c-type lysozymes in grass carp Ctenopharyngodon idellus. Dev Comp Immunol 34:501-509.

Yin ZX, He JG, Den WX, Chan SM (2003) Molecular cloning, expression of orangespotted grouper goosetype lysozyme cDNA, and lytic activity of its recombinant protein. Dis Aquat Org 55:117-123.

Zapata A, Díez B, Cejalvo T, Gutiérrez-de Frías C, Cortés A (2006) Ontogeny of the immune system of fish. Fish Shellfish Immunol 20:126-136.

Zapata AG, Torroba M, Varas A, Jiménez E (1997) Immunity in fish larvae. Developments in Biological Standardizations 90:23-32.

Zheng W, Tian C, Chen X (2007) Molecular characterization of goose-typelysozyme homologue of large yellow croacker and its involvement in immuneresponse induced by trivalent bacterial vaccine as an acute-phase protein. Immunol Lett 113:107-116. 